\title{
Mg Sm Ferrite for Nano structured E-Shaped Patch Antenna studies
}

\author{
Vasant Naidu \\ Professor/ECE \\ Sethu Inst. of Tech., \\ Pulloor - 626115, \\ Tamilnadu, India
}

\author{
M. Ashok Kumar \\ Scholar./ECE \\ Sethu Inst. of Tech., \\ Pulloor - 626115, \\ Tamilnadu, India
}

\author{
S.K.A. Ahamed \\ Kandu Sahib \\ Asso.Professor./ \\ ECE,Sethu Inst. of Tech. \\ Pulloor 626-115, \\ Tamilnadu, India,
}

\author{
Chandra Prakash \\ Additional Director \\ D.R.D.O, \\ New Delhi-110 011, \\ India.
}

\begin{abstract}
:
In this paper we have introduced $\mathrm{Mg} \mathrm{Sm}_{\mathrm{x}} \mathrm{Fe}_{2-\mathrm{x}} \mathrm{O}_{4}$ coated on RT DUROID5880 as substrate for an effective constituent to have a patch antenna. Here $\mathrm{Mg} \mathrm{Sm} \mathrm{Sm}_{\mathrm{x}} \mathrm{Fe}_{2-\mathrm{x}} \mathrm{O}_{4}$ of different thickness was coated over RT DUROID 5880 with dielectric constant of 2.2 and loss tangent of 0.0004 . This combination forms a new substrate for $\mathrm{E}$ shaped micro strip patch antenna design. It was found that the dielectric constant was reduced to 1.12 and loss tangent to 0.00046 . The thickness value of the combination was kept 15 mile, 13 mile, 12 mile, 11 mile and 10 mile. The simulation was performed using IE3D simulator for a frequency range of $5 \mathrm{GHz}$ to $15 \mathrm{GHz}$. The Return loss was $21.5322 \mathrm{~dB}$, VSWR value was 1.18306 , the Directivity came to be $8.37864 \mathrm{dBi}$, the Gain was $11.6778 \mathrm{dBi}$. The Efficiency came to be $98 \%$, these simulated results were encouraging.
\end{abstract}

Key words: IE3D SIMULATOR; RT Duroid; Micro strip E patch antenna; Nano ferrite materials ; Loss tangent, Relative permittivity

\section{INTRODUCTION}

In the recent trends, the ferrites find wide technological applications, as being the high-density materials [1-3]. Synthesis of nanometer size particles proved to be one of the interesting parts of material science in for various and technological applications. The small size particles have some of the interesting properties as compared to bulk particles, such as improved catalytic, dielectric and magnetic properties, as they possess high resistivity and negligible eddy current losses [4]. Due to the ever growing demand on multiband antenna and multi function antenna to be utilized in space and military applications, wearable antenna designs have received enormous attention.[5].Quite recently, application of new nano ferrite materials instead of the traditional ferrites has led to the development of low-cost, lightweight antennas that are easily integrated into electrical circuit. Using these nano ferrites, we can actually create micro strip patch (MPA) antenna that will lead to more efficient ways of transmitting and receiving electromagnetic radiations [6].Principal requirements for an antenna are low profile and small size, ability to minimize the radiation absorption MPAs appear to be more suitable for miniaturized applications. We have designed MPA using lanthanide substituted Magnesium ferrite coated over the dielectric substrate (RT DUROID 5880). As conductivity is one of the material characteristics that determines antenna parameters and eventually performance. Due to the light weight, low volume, low fabrication cost, and capability of dual and triple frequency operations MPA are playing dominating in the antenna applications. However the MPA suffer from a number of disadvantages. Narrow bandwidth is a serious limitation of these MPA. Different techniques are used to overcome this narrow bandwidth limitation. These techniques include increasing the thickness of the dielectric substrate, decreasing dielectric constant [7], it was found that the return loss at a frequency range $2.5 \mathrm{GHz}$ was less than $33 \mathrm{db}$, similarly the VSER was 1.5 for the substrate[7].In the Design and Optimization of Dual Band Micro Strip Antenna using Practical Swarm Optimization technique for maximizing the return loss for Frequency at $2.4 \mathrm{GHz}$ for dual band was found to be $-43.95 \mathrm{~dB}$ and for $3.08 \mathrm{GHz}$ was $-27.4 \mathrm{~dB}[8]$. for the Compact $\mathrm{L}$ shaped Micro strip patch antenna it was found that the band width increased up to $13.7 \%$ [9-11]. Studies had been performed for different shaped patch antennas such as L shaped, Inverted L shaped, U shape and Inverted U. It was found that the band width and the gain was improved for the uniplaner photonic band gap structure [12]. In continuation to these studies we had developed a new wide band stacked E shaped micro strip patch antenna, thus to solve the problem of narrow band width for enhancing band width and gain [13]. we have used the low permittivity value of $\mathrm{Mg} \mathrm{Sm} \mathrm{Fe}_{2-\mathrm{x}} \mathrm{O}_{4}$ ceramics to design the E-Shape patch antenna to study the Return loss, Gain, Electric field study through Smith chart and VSWR Studies, here we have coated the ferrite material over the RT DUROID 5880 substrate for the decreasing permittivity and loss tangent for a wider band.

\section{EQUATIONS FOR SIMULATION}

The designed antenna is a $3 \_3$ array. The _first step in the design is to specify the dimensions of a single micro strip patch antenna. The patch conductor can be assumed at any shape, but generally simple geometries are used, and this simplies the analysis and performance prediction. Here, the half-wavelength rectangular patch element is chosen as the array element (as commonly used in micros trip antennas) [14]. Its characteristic parameters are the length L, the width $\mathrm{w}$, and the thickness h, as shown in Figure 1.

Theoretical analysis and calculations[15] from of all dimensions will be obtained; the essential parameters for the design are:

$$
\begin{aligned}
& \mathrm{f}=5 \mathrm{GHz} \\
& \varepsilon_{\mathrm{r}}=1.12 \\
& \mathrm{~h}=0.1 \mathrm{Cm}
\end{aligned}
$$




\subsection{Calculation of the Width (W):}

The width of the patch element (W) is given by.

$\mathrm{W}=\frac{\mathrm{C}}{2 \mathrm{f}_{0} \sqrt{\frac{\left(\epsilon_{\mathrm{r}}+1\right)}{2}}}$

Substituting $\mathrm{c}=3 \times 108 \mathrm{~m} / \mathrm{s}, \varepsilon_{\mathrm{r}}=1.12$, and $\mathrm{f}_{\mathrm{o}}=5 \mathrm{GHz}$, we get,

$\mathrm{W}=2.91 \mathrm{~cm}$

\subsection{Calculation of Effective dielectric constant ( $\varepsilon$ reff ):}

The effective of the dielectric constant $\left(\varepsilon_{\text {reff }}\right)$ depending on the same geometry $(\mathrm{W}, \mathrm{h})$ but is surrounded by a homogeneous dielectric of effective permittivity $\varepsilon_{\text {reff }}$, whose value is determined by evaluating the capacitance of the fringing field

$\epsilon_{\text {reff }}=\frac{\epsilon_{\mathrm{r}}+1}{2}+\frac{\epsilon_{\mathrm{r}}-1}{2}\left[1+12 \frac{\mathrm{h}}{\mathrm{w}}\right]^{\frac{1}{2}}$

Substituting $\varepsilon_{\mathrm{r}}=1.12, \mathrm{~W}=2.91 \mathrm{~cm}$, and $\mathrm{h}=0.15 \mathrm{~cm}$, then $\varepsilon_{\text {reff }}=1.14 \mathrm{~cm}$

\subsection{Calculation of the Effective length ( eff}

L ):

$\mathrm{L}_{\text {eff }}=\frac{\mathrm{C}}{2 \mathrm{f}_{0 \sqrt{\epsilon_{\text {reff }}}}}$

Substituting $\mathrm{c}=3 \times 108 \mathrm{~m} / \mathrm{s}$, $\operatorname{reff}=1.14 \mathrm{~cm}$, and $\mathrm{f}_{\mathrm{o}}=5 \mathrm{GHz}$, then $\mathrm{L}_{\mathrm{eff}}=2.81 \mathrm{~cm}$

\subsection{Calculation of the length extension $(\Delta \mathrm{L}$}

):

$\Delta \mathrm{L}=0.412 \mathrm{~h} \frac{\left(\epsilon_{\text {reff }}+0.3\right)\left(\frac{\mathrm{W}}{\mathrm{h}}+0.264\right)}{\left(\epsilon_{\text {reff }}-0.258\right)\left(\frac{\mathrm{W}}{\mathrm{h}}+0.8\right)}$

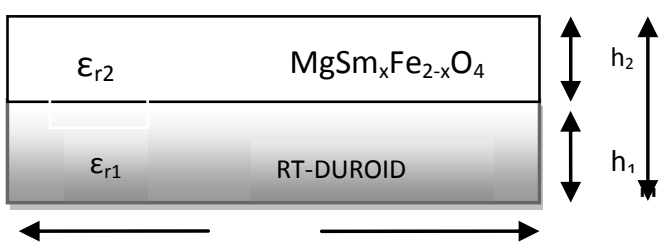

$\mathrm{L}$

Fig 1 Description of the $\mathrm{MgSmxFe} 2-\mathrm{xO} 4$ coated RTDUROID 5880, $\mathrm{h}_{1}=0.09 \mathrm{~cm}, \mathrm{~h}_{2}=0.1 \mathrm{~cm}$ and $\mathrm{L}=2.81 \mathrm{~cm}$
Substituting $\mathrm{E}_{\text {reff }}=1.14 \mathrm{~cm}, \mathrm{~W}=2.3717 \mathrm{~cm}$, and $\mathrm{h}=0.15 \mathrm{~cm}$, then $\Delta \mathrm{L}=0.0982 \mathrm{~cm}$

\subsection{The actual length $(L)$ of patch}

$\mathrm{L}=\mathrm{L}_{\mathrm{eff}}-2 \Delta \mathrm{L}$

Substituting $\Delta \mathrm{L}=0.0982 \mathrm{~cm}$, and $\mathrm{L}_{\text {eff }}=2.81 \mathrm{~cm}$, then $\mathrm{L}=2.61 \mathrm{~cm}$

Strip patch length and width calculated by Ansoft disigner Sv 2.10 version

\section{ANTENNA DESCRIPTION}

The results of the nano material coated RT DUROID for the proposed E-Shaped MSPA was simulated using IE3D Simulator with optimization. The software used to model and simulate the microstrip patch antenna is Zeland Inc's IE3D software. IE3D is a full-wave electromagnetic simulator based on the method of moments. It analyzes $3 \mathrm{D}$ and multilayer structures of general shapes. It has been widely used in the design of MICs, RFICs, patch antennas, wire antennas, and other RF/wireless antennas. It can be used to calculate and plot the $11 \mathrm{~S}$ parameters, VSWR, current distributions as well as the radiation patterns.

The Proposed antenna has:Proposed Patch length $=2.81 \mathrm{~cm}$ Proposed Patch Width $=2.91 \mathrm{~cm}$ Strip Path Length $=1.4322 \mathrm{~cm}$ Strip Path Width $=0.46189 \mathrm{~cm}$ Cut width $=1.16 \mathrm{~cm}$ Cut depth $=1.16 \mathrm{~cm}$

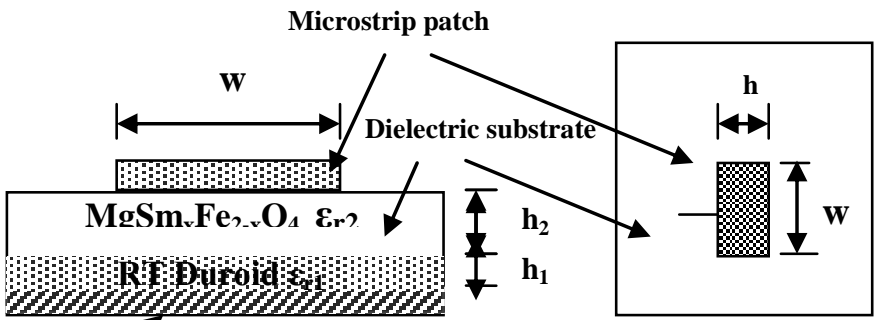

Metal Ground

\section{SIDE VIEW}

TOP VIEW

Fig 2 Antenna Layout 


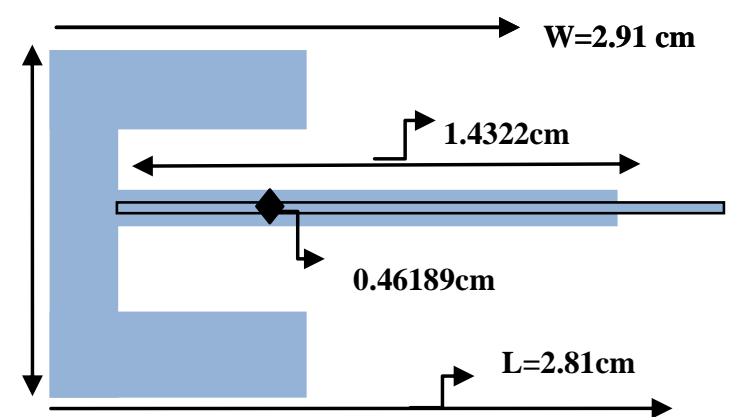

Fig 3 Block Diagram of proposed Antenna

\section{RESULT AND DISSCUSSIONS}

Comparison of Different Micro strip Patch Antenna in Different thickness by using optimization in IE3D Simulator for RT DUROID 5880 Substrate. The simulated data's obtained from IE3D were used to plot the graphs. These graphs has been traced by using MATLAB R2009b shown as figure 5-25.It is seen in graph 5

\subsection{Thickness when $h=0.15 \mathrm{~cm}$}

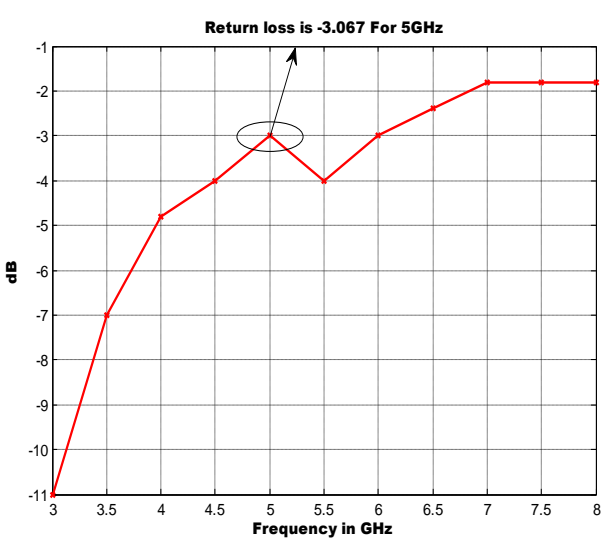

Fig 5 Return loss Vs Frequency (in GHz)

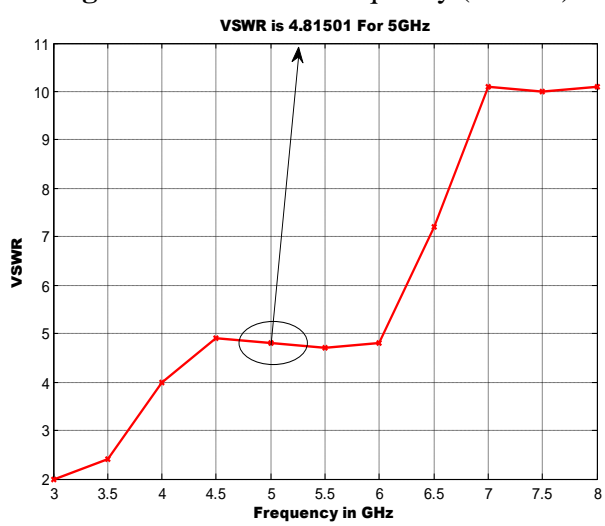

Fig 6 VSWR Vs Frequency (in GHz)

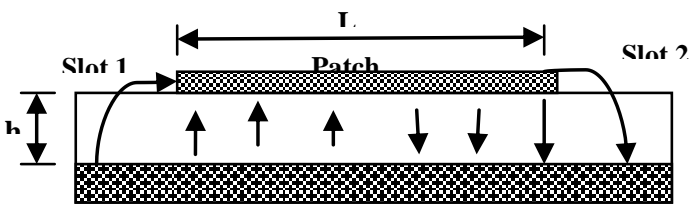

Ground plane

RADIATING PATCH ANTENNA

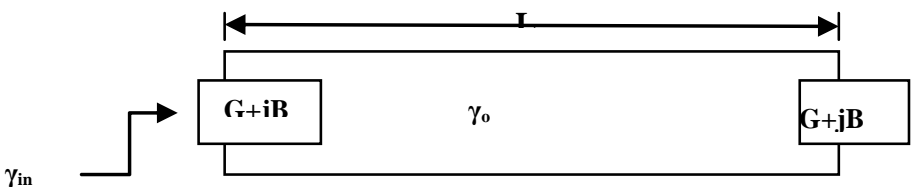

EQUIVALENT CIRCUIT

Fig 4 Equivalent circuit diagram

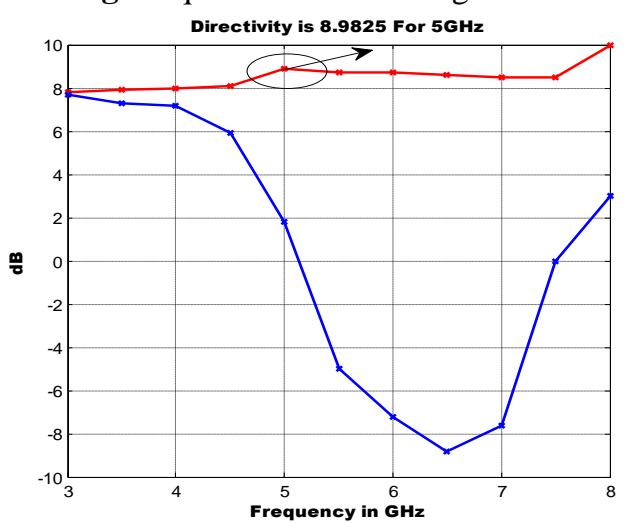

Fig 7 Directivity Vs Frequency (in GHz)

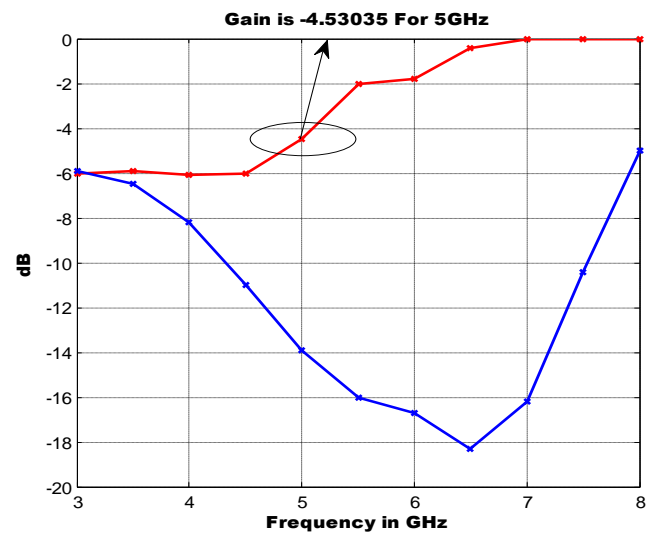

Fig 8 Gain Vs Frequency (in GHz)

\subsection{Thickness when $h=0.13 \mathrm{~cm}$}

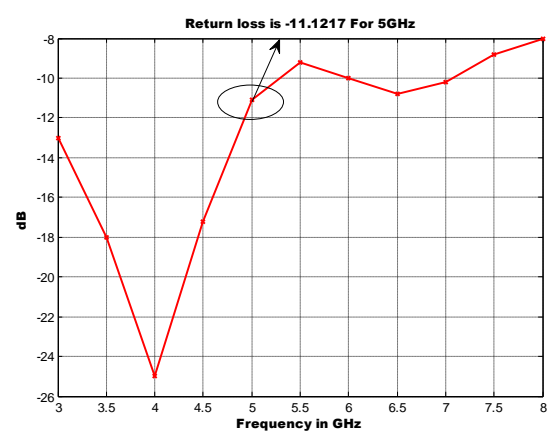

Fig 9 Return loss Vs Frequency (in $\mathrm{GHz}$ ) 


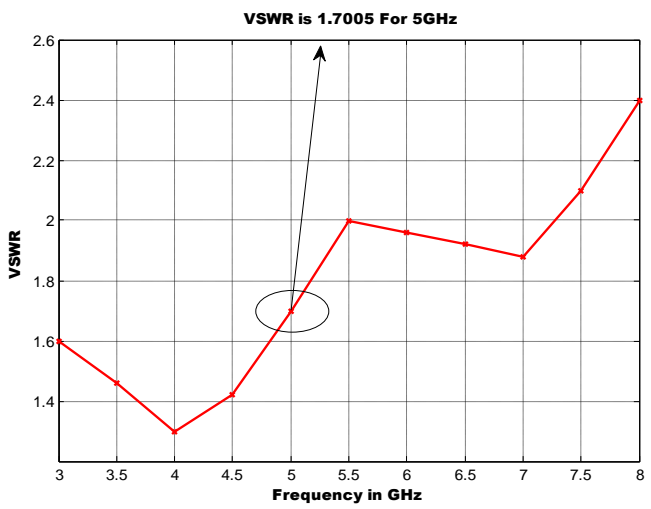

Fig 10 VSWR Vs Frequency (in GHz)

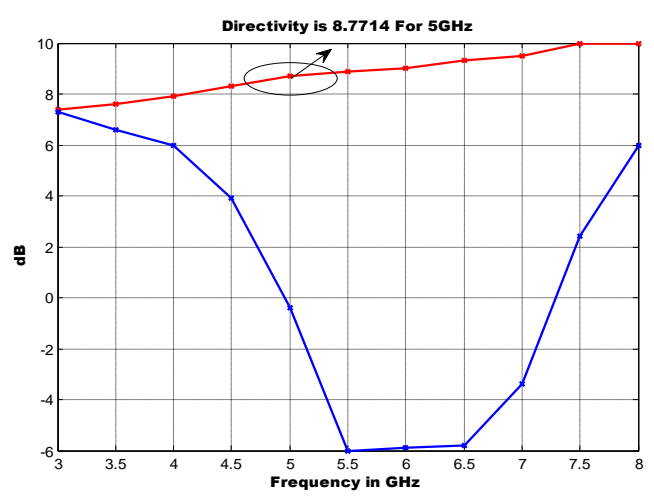

Fig 11 Directivity Vs Frequency (in GHz)

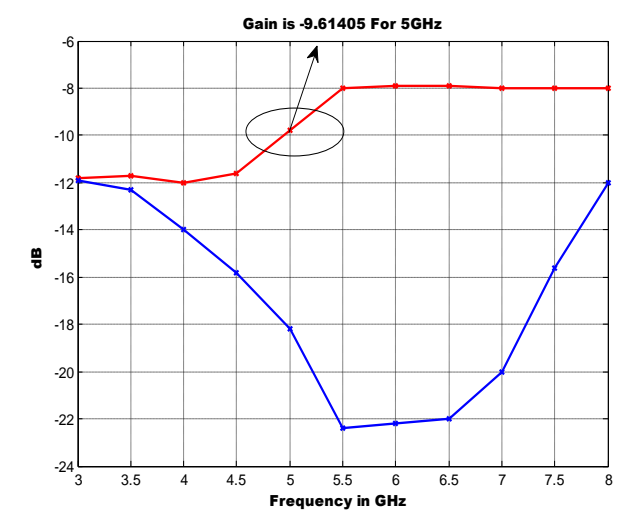

Fig 12 Gain Vs Frequency (in GHz)

\subsection{Thickness when $h=0.11 \mathrm{~cm}$}

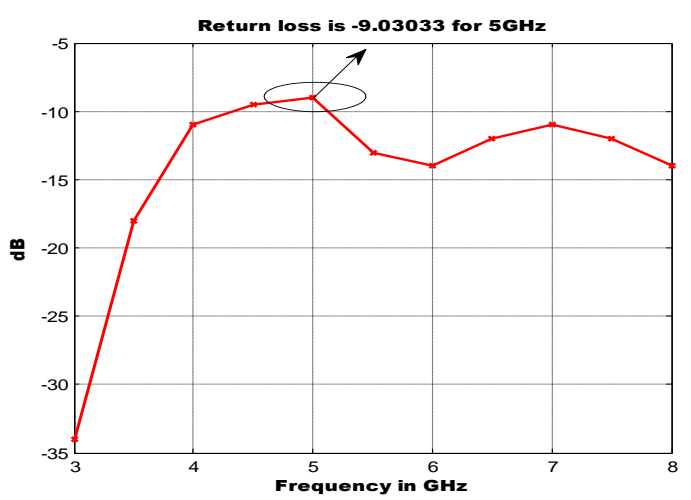

Fig 13 Return loss Vs Frequency (in GHz)

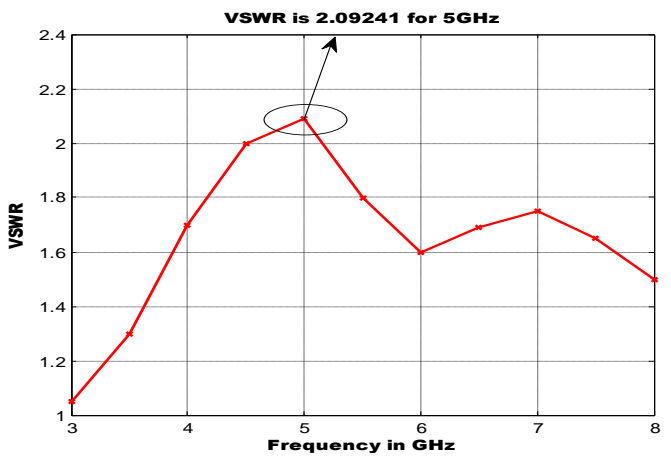

Fig 14 VSWR Vs Frequency (in GHz)

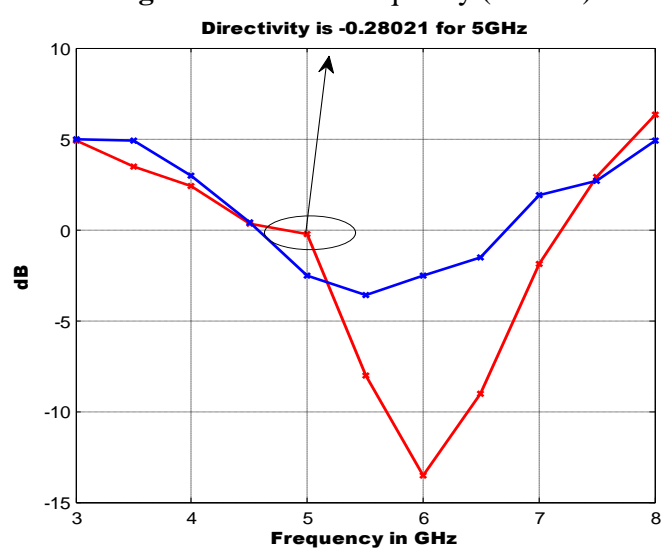

Fig 15 Directivity Vs Frequency (in GHz)

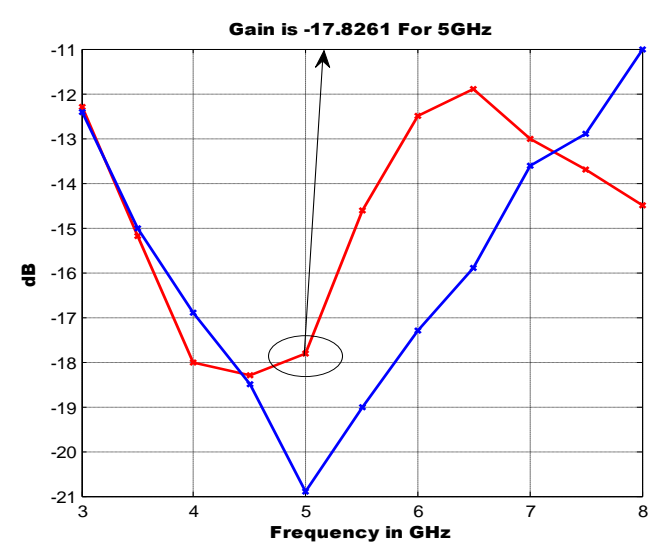

Fig 16 Gain Vs Frequency (in GHz)

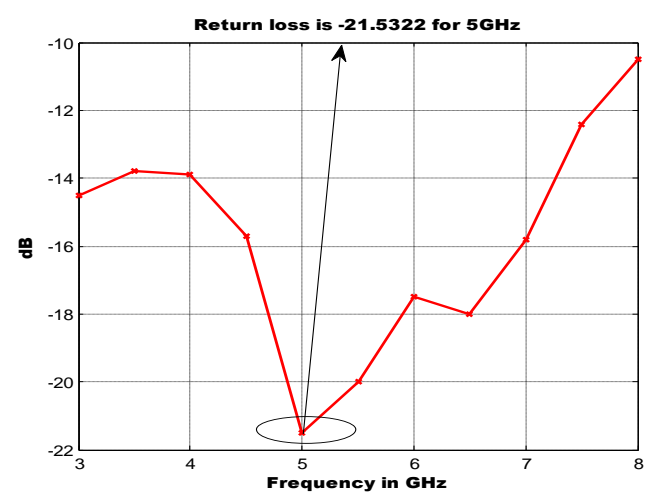

Fig 17 Return loss Vs Frequency (in GHz) 


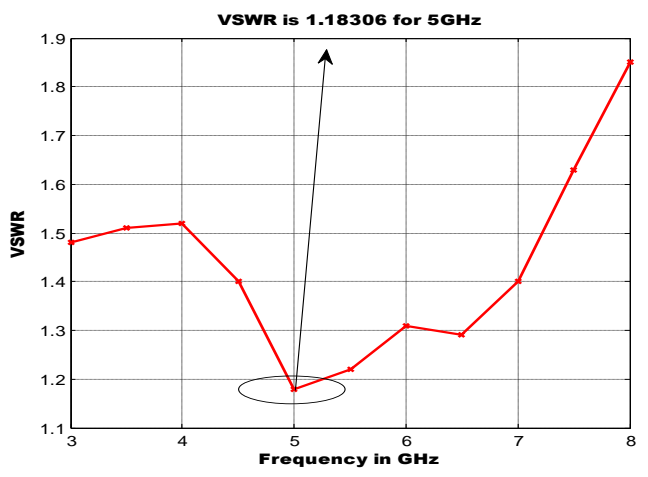

Fig 18 VSWR Vs Frequency (in GHz)

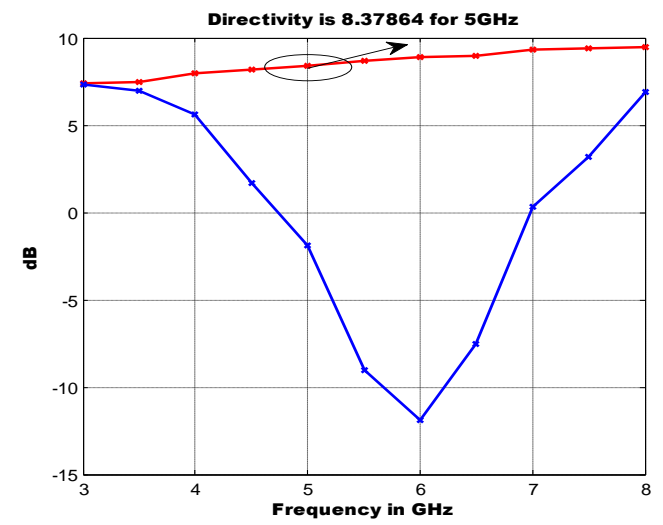

Fig 19 Directivity Vs Frequency (in $\mathrm{GHz}$ )

\begin{tabular}{|c|c|c|c|c|c|}
\hline S.N & $\begin{array}{c}\text { Thick } \\
\text { ness } \\
(\mathbf{c m})\end{array}$ & $\begin{array}{c}\text { Return } \\
\text { loss } \\
(\mathbf{d B})\end{array}$ & VSWR & $\begin{array}{c}\text { Directivit } \\
\mathbf{y} \\
(\mathbf{d B i})\end{array}$ & $\begin{array}{c}\text { Gain } \\
(\mathbf{d B i})\end{array}$ \\
\hline 1 & 0.15 & -3.067 & 4.8150 & 8.9825 & -4.5304 \\
\hline 2 & 0.13 & -11.122 & 1.701 & 8.7714 & -9.6141 \\
\hline 3 & 0.11 & -9.0303 & 2.0924 & -0.28021 & -17.83 \\
\hline 4 & 0.10 & -21.532 & 1.1831 & 8.37864 & -11.68 \\
\hline
\end{tabular}

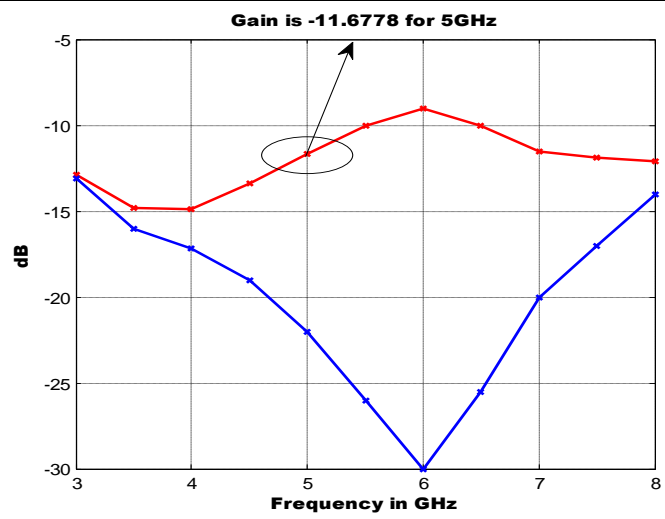

Fig 20Gain Vs Frequency (in GHz)

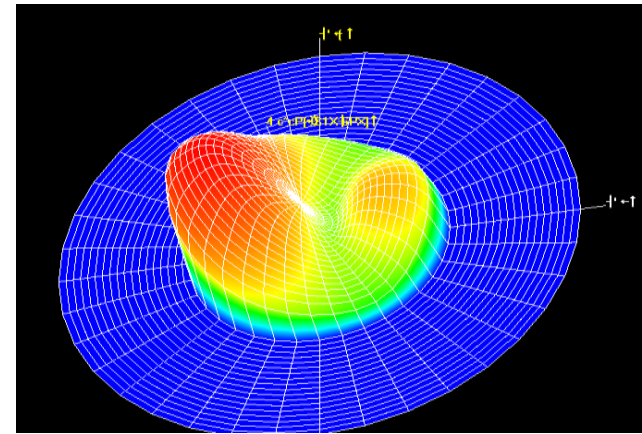

Fig 21 Radiation pattern for thickness $0.15 \mathrm{~cm}$

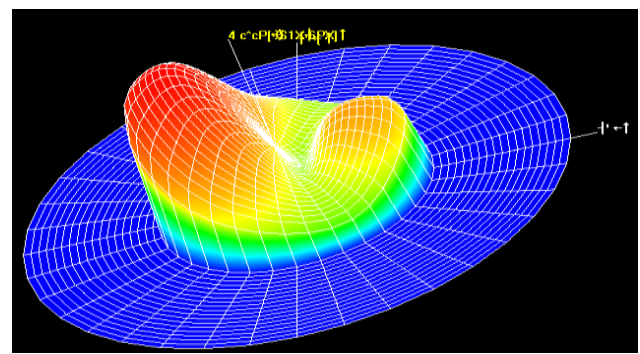

Fig 25 Radiation pattern for thickness $0.13 \mathrm{~cm}$

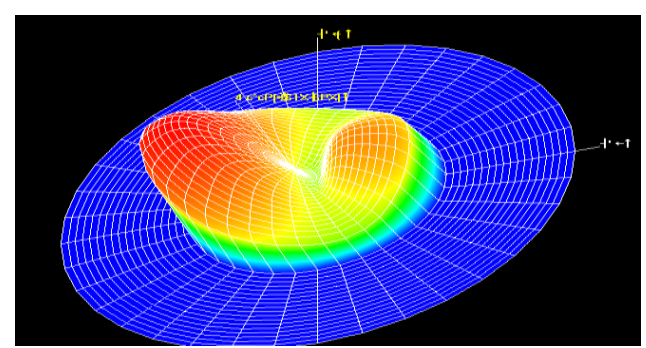

Fig 26 Radiation pattern for thickness $0.11 \mathrm{~cm}$

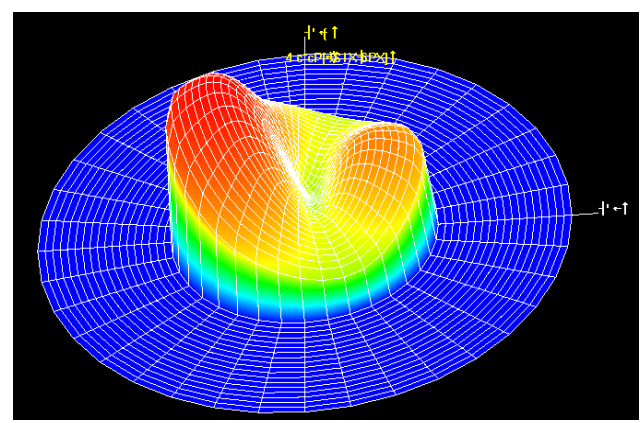

Fig 24 Radiation pattern for thickness $0.10 \mathrm{~cm}$

We clearly demonstrated that the sense of the antenna polarization is strongly influenced by the $\mathrm{Mg} \mathrm{Sm} \mathrm{Sm}_{2-\mathrm{x}} \mathrm{O}_{4}$ substrate since it changes at will in respect to the direction of the external magnetic field. For thickness $0.1 \mathrm{~cm}$, the Return loss is $21.5322 \mathrm{~dB}$, VSWR value is 1.18306 , the Directivity is $8.37864 \mathrm{dBi}$, and the Gain is $11.6778 \mathrm{dBi}$, the Efficiency is $98 \%$.It is more effective than other thicknesses $(0.15 \mathrm{~cm}$, $0.13 \mathrm{~cm}, 0.11 \mathrm{~cm})$. The proposed antenna give best result when antenna has standard thickness is 10 mile. 


\section{CONCLUSIONS}

Concluding, we introduced the utilization of ferrimagnetic compound, namely $\mathrm{Mg} \mathrm{Sm} \mathrm{Fe}_{2-\mathrm{x}} \mathrm{O}_{4}$ as a substrate in patch antennas in an effort to tune the radiation characteristics by means of an externally controlled parameter. Especially, in this work we focused on changing and controlling the polarization under the application of an external dc magnetic field. If the concentration of $\mathrm{Sm}$ is increased to higher percentage. The expected result will be further encouraging and this antenna will be applicable to a wider band.

\section{ACKNOWLEDGMENT}

This work was partly funded under DRDO project, No. ERIP/ER/0704407/M/01.

\section{REFERENCES}

[1] M A Jacob.John, Khadar, Lonappan.Anil and K.T Mathew, Microwave dielectric properties of nano structured nickel ferrite, Bull, Mater. Sci,31- 6.(2008) pp. 847-851.

[2] Vasant Naidu, S.K.A. Ahamed KanduSahib, M.SheikDawood, M.Suganthi; Magnetic Properties of Nano Crystalline Nickel, Samariumdoped Zinc Ferrite, International Journal of Computer Applications,24-2, (June 2011),pp. 0975 - 8887.

[3] Vasant Naidu, S.K.A.Ahamed KanduSahib, M.SheikDawood, M.Suganthi; Magnetic Properties of Nano Crystalline Nickel, Cerium doped Zinc Ferrite, International Journal of Nano tech and Nano Sci in press.

[4] A.T Raghavendera., Damir Pajic, kreso Zadro,Tomislav Milekovic, Venkateshwar Rao.P. Jadhav K M and Ravinder D,Synthesis and Magnetic properties of $\mathrm{NiFe}_{2}$ ${ }_{x} \mathrm{Al}_{x} \mathrm{O}_{4}$ nano particles, Mag $\mathrm{J}$ and Mag Mat, 1 (2007). pp 316

[5] Burke P.J, S.Li and Z. Yu, Quantitative theory of nanowire and nanotube antenna performance Nanotechnology, IEEE transactions on, 2006, 5(4); p 314-334.

[6] Demoustier, S., et al., Review of two microwave applications of carbon nanotubes: nano-antennas and nano-switches. Comptes Rendus Physique, 2008. 9(1): p. 53-66.

[7] Ahmed H. Reja "Study of Micro Strip Feed Line Patch Antenna", Antennas and Propagation International Symposium, vol. 27, pp. 340-342 December 2008.

[8] Sahntanu Kumar Behera and Y. Choukiker, "Design and Optimization of Dual Band Micro Strip Antenna Using Practicle Swarm Optimization Technique," in Springer Science+Business Media, LLC, pp. 1346-1354, 2010

[9] A. A. Deshmukh and G. Kumar, "Compact broadband gap-coupled shorted L-shaped microstrip antennas," in IEEE Antennas and Propagation International Symposium, vol 1, (Baltimore, Maryland), pp. 106-109, IEEE, July 2001

[10] Z. M.Chen and Y.W.M. Chial, "Broadband probe-fed Lshaped plate antenna," Microwave and Optical Technology Letters, vol. 26, pp. 204-206, 1985.

[11] K. F. Lee, K. M. Luk, K. F. Tong, Y. L. Yung, and T. Huynh, "Experimental study of the rectangular patch with a U-shaped slot," in IEEE Antennas and Propagation International Symposium, vol. 1, (Baltimore, Maryland), pp. 10-13, IEEE, July 1996.

[12] S. C. Gao, L. W. Li, M. S. Leong, and T. S. Yeo, "Design and analysis of a novel wideband microstrip antenna," in IEEE Antennas and Propagation International Symposium,vol. 1, (Boston, Massachusetts), pp. 90-93, IEEE, July 2001.

[13] M. Khodier and C. Christodoulou, "A technique to further increase the bandwidth Of stacked microstrip antennas," in IEEE Antennas and Propagation International Symposium, vol. 3, (Salt Lake City, Utah), pp. 1394-1397, IEEE, July 2000.

[14] Neenansha Jain, Anubhuti Khare, Rajesh Nema “" EShape Micro strip Patch Antenna on Different Thickness for pervasive Wireless Communication" (IJACSA) International Journal of Advanced Computer Science and Applications, Vol. 2, No. 4, 2011

[15] C.A.Balanis "Antenna Theory Analysis and Design" 1938. 